Table 1. SPACINGS $(\AA)$ OF MERIDIONAL ( $M$ ) AND NEAR-MERIDIONAL REFLEX IONS FROM Proteus FLAGELLA (ref. 2) AND ACTIN FILAMENTS (ref. 7 )

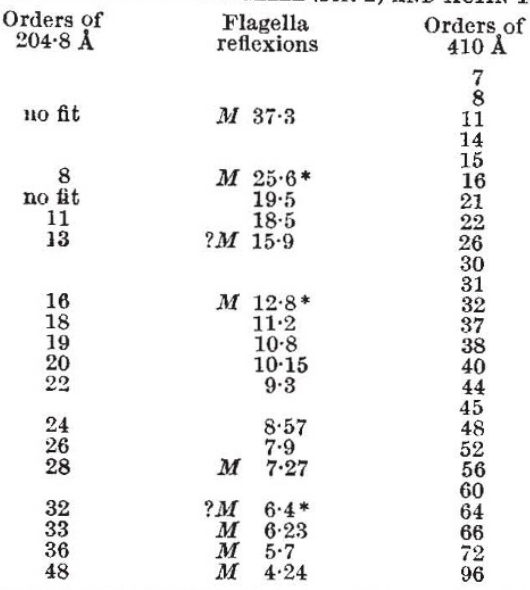

- Reflexions indicating axial separation of sub-units.

(personal communication); we have not yet attempted to test our model by reference to the equatorial diffraction data.

The methods we have used reveal only the surface structure of the flagellum. Whatever material lies inside is of unknown structure. We have found that neither uranyl nor phosphotungstate penetrates inside, even where flagella are broken. This indicates that the flagella are not hollow, in contrast to previous findings ${ }^{2,3}$. but these had been obtained using detached water-washed flagella, whereas our observations were made on untreated flagella. Sheaths were often observed on the flagella of Proteus in our preparations, though not on Pseudomonas flagella. The sheath appears to be less than $50 \AA$ thick. Its profile shows periodic indentations, spaced at intervals of about $100 \AA$; possibly, therefore, the sheath is helically organized.

Comparing bacterial flagella with muscles, Astbury et $a l .{ }^{2}$ noted that in each system the axial X-ray reflexions could all be indexed as orders of a $410 \AA$ repeat (Table 1). But it is now known that only one of the two components of the contractile system in muscle, the thin actincontaining filament, has a $410 \AA$ periodicity ${ }^{4,5}$; the myosin-containing filament has a structure which repeats at intervals of multiples of $145 \AA$, for example, $435 \AA$ in vortebrate skeletal muscle ${ }^{4}$. Whether or not there is more than one component (and periodicity) in bacterial flagella remains to be shown. The $410 \AA$ periodicity of the thin filaments in muscle is very likely due to a complex of $F$-actin with tropomyosin $B$ (ref. 5 ), in which the double helix of $F$-actin repeats at $410 \AA$ intervals, that is, the two helically wound strands of globular sub-units cross over one another at these intervals (Fig. 4). The comparable periodicity in bacterial flagella is the pitch of the helix of sub-units, but this does not measure $410 \AA$ in either Pseudomonas or Proteus, though in the latter it moasures one-half of $410 \AA$. The actual value is of no

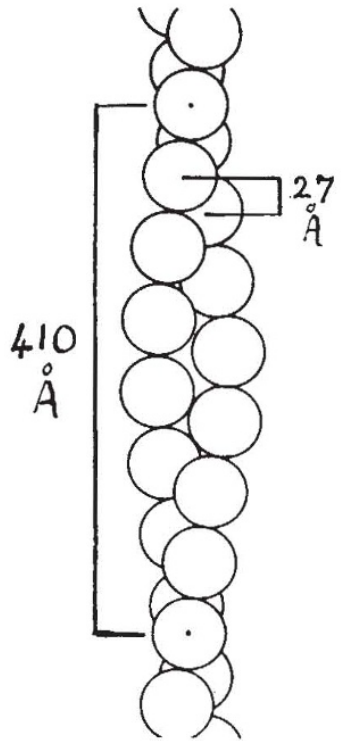

Fig. 4. Sub-unit arrangement in $F$-actin with $410 \AA$ periodicity

obvious significance. Clearly, it would be useful to examine the diffraction pattern of Pseudomonas for any evidence of a $410 \AA$ repeat.

$F$-actin filaments have been found in many different types of muscles, in fact, in every example so far examined ${ }^{5}$. Whereas the structure of myosin-containing filaments varies widely in different muscles ${ }^{4,6}$, that of actin filaments is constant. Therefore it is of intorest to find that an actin filament and the periphery of a bacterial flagellum are constructed on similar principles: each consists of helically arranged globular sub-units. Moreover, the sub-units in the two systems may bo comparable in size, judging from their spacing (ef. Figs. 3 and 4 and the diffraction data in Table 1 ).

It is still unknown what, if any, structural changes occur in muscle filaments during contraction. This is $a$ difficult problem to tacklo directly. Possibly relevant information may be obtained indirectly by discovering configurational changes at the molecular level in nonmuscular contractile systems such as bacterial flagella. This will be one of the main objects of future experiments, and in particular we shall attempt to explain the significance of the two observed types of flagellar fine structure.

${ }^{1}$ Kerridge, D., Horne, R. W., and Glauert, A. M., J. Mol. Biol., 4, 227 (1962). ${ }^{2}$ Astbury, W. T., Beighton, E., and Weibull, C., Symp. Soc. Exp. Biol., 9, $282(1955)$

${ }^{3}$ l3urge, R. E., Proc. Roy. Soc., A, 260, 558 (1961).

4 Elliott, G. F., and Worthington, C. R., J. Physiol., 149, 32P (1959) Worthington, C. R., J. Mol. Biol., 1, 398 (1959). Elliott, G. F., Proc. Roy. Soc., B (in the press).

'Hanson, J., and Lowy, J., J. Mol. Biol., 6, 46 (1963). Hanson, J., and Lowy, J., Proc. Roy. Soc., B (in the press).

'Lowy, J., and Hanson, J., Physiol. Rev., 42, Suppl. 5, 34 (1962).

${ }^{7}$ Selby, C. C., and Bear, R. S., J. Biophys. Biochem. Cytol., 2, 71 (1956).

\title{
OBITUARIES
}

Prof. N. Wiener

THE recent death of Norbert Wiener has ended a mathematical and scientific career of rare distinction and influence, and has brought a deep sense of loss not only to those who knew him as a sciontist, teacher or friond, but also to the many more who found inspiration in his work and gained fresh insight through his exposition.

Wiener was born on November 26, 1894, and his father, Leo Wiener, was professor of Slavonic languages and literature in Harvard University. After attending high school in Massachusetts, Wienor went to Tufts College and Harvard and Cornell Universities bofore going to Europe for further postgraduate study with Russell, Hardy and Littlewood in Cambridge, and Hilbert in Göttingen. After this relatively short period, he resumed his deop and life-long attachment to Now England, and his association with the Massachusetts Institute of Technology, beginning with his appointment as an instructor in mathematics in 1919, remained unbroken for the rest of his life. 
Although the range of his mathematical interests was wide and led him to significant advances, for example, in logic, mechanics and potential theory, there is no question that his main impact on mathematics has been through the closely related fields of harmonic analysis and the theory of stochastic processes.

Wiener's interest in tho first field was first stimulated by his association with Hardy and Littlewood at a time when their deep and pioneering work on Tauberian theorems for the classical summability processes still appeared to lack a general and unifying principle. This Wiener supplied in the form of his famous general Tauberian theorem and the equivalent result on the closure of translations of integrable functions on the real line. This was recognized immediately as a result of great significance in the study of convolution transforms, including as it did the classical results of Hardy and Littlewood as special cases, and it remains one of the most central and beautiful theorems of analysis. Indeed, it has come to occupy an even more central place in modern mathematics through the achievements of Gelfond and others in fitting it and its many generalizations into a more fundamental algebraic framework. Although Wiener himself never expressed his results in the terminology of the theory of Banach algebras that is now custom. ary, it is clear from his proofs that the essential idea of convolution as an algebraic oporation in an appropriate function space was very much in his mind, and many of the methods and techniques that he introduced are still the most natural and powerful ones.

The successful use of the Fourier transform in Tauberian theory led Wiener to the deeper examination of the nature of harmonic analysis and the major now concepts set out in his book The Fourier Integral (1933). His aim was to examine how far, and under what conditions, a genoral function $f(x)$ could be "analysed harmonically" as a Fourier integral $\int e^{i t x} \mathrm{~d} F(t)$. His results in this direction and through the concept of the "harmonic spectrum" of a function have proved of vital importance in physics and other applications, and have provided a great stimulus in the development of contemporary theories of distributions and abstract harmonic analysis.

The methods of this first book were taken into wider and even more difficult fields by his work with Paley on the Fourier Integral in the Complex Domain, and published jointly in a famous book of that name.

These two books contained also Wiener's first formula. tion of the third major theory which occupied his attention for the rest of his life. This was the theory of stochastic processes and, as was natural and inevitable, their harmonic analysis. He was very much influenced in all his work by physical problems and had long boen interested in cortain probloms of statistical bohaviour and, in particular, in the phenomonon of Brownian motion of small particles suspended in fluids. There was at the time no satisfactory mathematical formulation of this, or even the tools to make it possible, and Wiener's great achievoment here was to provide such a formulation in a way which made good sense physically and was mathematically rigorous and capable of wide and fundamentally important generalization. The mathematical result was the proof that a random function (or stochastic process) could be described by the specification of a measure (in the Lebesque sense) in a space of functions in such a way that the measure of certain sets could be assigned. This is still one of the main problems in the modern thoory of stochastic processes.

The idea of the harmonic analysis of a random process may well be regarded as the synthesis of his work, because it is on this that his contribution to the theory of cybornetics is based. His main ideas have beon set out in many papers and, in shorter form, in the books The Extrapolation, Interpretation and Smoothing of Stationary Time Series (1949), Non-Linear Problems in Random Theory (1958) and Cybernetics (1948 and 1961). He has often beon deseribed as the "father of eybernetics", and there is no doubt that his work and his advocacy have both had a decisive influence on the whole development of the subject. He was one of the first to see the close connexion betwoen the physical theorios of transmission of information, feed-back and control and the action of the human brain; and his work in this direction over the past years has done much to establish what is plainly to become a vital field of fundamontal research.

Wiener was conscious in all his work of its possible applications and offects, and ho was particularly concerned about the long-term implication of automation, which he clearly and quite rightly saw as one of the basic social (as distinct from scientific) problems of our age. In fact, this concern was only to be expected of a man who had always a very deep social and moral sense and who was as strongly incensed by injustice or cruelty in any form as by political folly and stupidity.

The same quality showed in his rolations with individuals. Fe was, it must be said, a truly formidable personality, both on account of his immonse erudition in fields unoxpectedly far from his own and by the intensity of his feelings and reactions: but this was fully matched by the depth of his concern for others (particularly when in difficulty or trouble) and by his habits of friondly and unaffected kindliness to the many who asked his help or sympathy.

He was, above all, as a friend and toacher an inspiration to a whole genoration of younger mathomaticians, and those who knew him best in this way will be most conscious of the privilege that was theirs and the debt that they owe him.

H. R. Pitт

\section{Dr. Georges Blanc}

North Africa is a fertile region for parasitologists; the story began with Alfonse Laveran, who discovered the malaria parasite in Algeria, and thereby stimulated a succession of his fellow countrymen along the coast to achievements almost comparable with his own. Thus in Tunis, Constantine, Algiers and Casablanca, Charles Nicolle, A. F. X. Henry, Edmond Sergent and Georges Blane, respectively, have made fundamental discoveries in tropical medicine during the course of this century. Georges Blanc died last year, and now, of these great Frenchmen, only Sergent and Henry remain.

Georges Blane was born in 1884 at Vauvers (Gard), and died on April 13, 1963. He graduated in science in 1907 and in medicine in 1911 . He learnt his formal parasitology under Blanchard, in the Faculté de Médecino of Paris, his protozoology as a junior colleague of Chatton, and his field work with Nicolle in Tunis. Nicolle said affectionately of Blane that of all his pupils Blane was the one who most resembled himself. With Chatton, he detected structures in Toxoplasma, almost submicroscopic in size, which, many years later, were found by electron mieroscopy to provide a new classification of the Sporozoa.

For twelve years (1920-32) Blane was the director of the Pasteur Institute of Athens, where he investigated parasitological problems of the northern coast of the Meditorranean; then for the next thirty years he directed the Pasteur Institute of Morocco, working on the allied problems of the southern coast. During the Second World War, he was marooned in France, but succeeded in getting back to North Africa with his cultures of micro-organisms; he reached Toulouse by train and then had to travel on foot for the next $400 \mathrm{~km}$ across the Pyrenees into Spain.

Blane was an eclectic worker, and any subjects that ho investigated became illuminated in unexpected directions. His observations on plague led him to believe that human fleas and lice play a much greater part in transmission than is usually thought, and that the organisms remain virulent in their excreta and corpses. $\mathrm{He}$ developed vaccines or sera against this disease, typhus and toxo- 